\title{
Economía de la coca y violencia: realidades desde el corregimiento de El Plateado, municipio de Argelia, Cauca (Colombia)
}

\author{
Economics of coca and violence: realities from the Corregimiento \\ of El Plateado, Municipality of Argelia, Cauca (Colombia)
}

Denis Antonio Arboleda Suárez Ingeniero agropecuario, Universidad del Cauca, magíster en Desarrollo Comunitario Sustentable, Universidad Nacional de Costa Rica, docente de la Institución Educativa Técnica Miguel Zapata, corregimiento de El Plateado (Colombia). Correo electrónico: dearsua@hotmail.com

Artículo de investigación DOI: http://dx.doi.org/10.15332/s2339-3688.2017.0001.02 Fecha de recepción: Abril 18 de 2017 • Fecha de aceptación: Octubre 5 de 2017

\section{RESUMEN}

El artículo hace parte de una investigación realizada en el marco de la tesis de maestría en Desarrollo Comunitario Sustentable de la Universidad Nacional de Costa Rica, titulada "Identidades, proyectos de vida y participación comunitaria de los jóvenes en el corregimiento de El Plateado, municipio de Argelia, Cauca”. Se presentan evidencias de la violencia vivida en el corregimiento en un contexto de cultivos ilícitos como resultado de una crisis institucional del Estado, abordando aspectos relacionados con la confrontación del aparato armado del Estado y los grupos guerrilleros, la arremetida paramilitar, efectos de las fumigaciones para la erradicación de cultivos de coca y la amenaza tras los intereses mineros en la zona.

Palabras clave: comunidad, historia, cocaína, narcotráfico, violencia, Colombia. 


\begin{abstract}
The article is part of a research developed in the frame of the Master's thesis on Sustainable Community Development of the National University of Costa Rica, titled "Identities, life projects and community participation of young people in the township of El Plateado, municipality of Argelia, Cauca". It is presented evidence of the violence experienced in the town in a context of illicit crops as a result of an institutional crisis of the State, dealing with aspects related to the confrontation of the armed apparatus of the State and guerrilla groups, the paramilitary attack, effects of fumigations for the eradication of coca crops and the threat after mining interests in the area.
\end{abstract}

Keywords: Community, history, cocaine, drug traffic, violence, Colombia.

\title{
INTRODUCCIÓN
}

Históricamente, Colombia ha sido un país con una gran debilidad institucional que no ha permitido generar procesos de desarrollo social y económico con equidad, al contrario, cada vez son más amplias las brechas sociales y económicas que separan a ricos y pobres, con una mayor marcación en algunos departamentos como la Guajira, Cauca y Chocó, los cuales presentan altos índices de desigualdad social reflejados en indicadores como altos niveles de inseguridad alimentaria y desnutrición. Como lo plantea Kalmanovitz (2007):

La hipótesis institucional dice que el crecimiento económico exige instituciones políticas y legales que lo apoyen, entre ellas sistemas incluyentes que apoyen la economía, Estados fuertes que ejecuten buenas políticas públicas, sistemas de educación universales y de calidad que permitan apropiar y adaptarse la tecnología. La falta de "buenas" instituciones puede explicar por qué numerosos países no pudieron aprovechar las oportunidades que abrieron las dos globalizaciones que se experimentaron desde el siglo XIX. (p. 44)

En este sentido, ante un estado social de derecho que no logró suplir las necesidades de sus habitantes y ante la carencia de instituciones eficaces capaces de generar procesos 
de desarrollo participativos en el territorio nacional, surgieron en la historia una serie de reclamaciones desde las bases populares, que terminó en el surgimiento de los movimientos guerrilleros, como también en la aparición de economías ilícitas que se convirtieron en el sustento económico y forma de vida de muchas comunidades campesinas a lo largo y ancho del territorio, situación donde el departamento del Cauca no fue la excepción.

Las economías del narcotráfico junto con la presencia de actores armados al margen de la ley establecieron otros patrones de vida y desarrollo económico en aquellos territorios con poca presencia institucional del Estado colombiano, proceso en el cual el desarrollo del conflicto armado ha dejado enormes secuelas en las poblaciones afectadas. La responsabilidad del Estado frente a la aplicación de una política fallida de lucha contra las drogas también ha tenido sus enormes repercusiones en las comunidades, acrecentándose la crisis social y humanitaria que padecen muchos campesinos en la ruralidad colombiana. Como lo indican Galindo, Restrepo y Sánchez (2009):

Las instituciones de justicia y de resolución de conflictos, de aplicación de la ley, de protección de los derechos de propiedad, del sistema electoral y, en general, de provisión de bienes públicos son producto de la historia. La estructura de este legado institucional, junto con características idiosincráticas de la historia colombiana [...], dieron nacimiento y forma al conflicto armado interno y a las condiciones actuales de pobreza en Colombia. (p. 317)

En este orden de ideas, el siguiente artículo recoge evidencias de los procesos de violencia y aparición de cultivos de coca como resultado de una ausencia institucional del Estado, que brindará condiciones suficientes para el desarrollo de economías lícitas desde un corregimiento llamado El Plateado, ubicado en el suroccidente del departamento del Cauca. Dicho corregimiento se encuentra localizado en el municipio de Argelia, lugar en el cual tienen encuentro una gran diversidad de habitantes provenientes de diferentes lugares del departamento y también de otros sitios del país, los cuales arriban, en su mayoría, con el interés de mejorar sus condiciones económicas tras la inserción en las diferentes actividades asociadas al cultivo y procesamiento de hojas de coca. 
En su historia se reconoce que desde su fundación hacia la década de 1950 en el corregimiento aún no existían los cultivos de coca con fines ilícitos, al contrario, en principio el sustento de sus habitantes se basó en los denominados cultivos de pancoger como maíz, yuca, plátano, chontaduro, arroz, entre otros, como también la cría de ganado porcino y bovino sin ningún tipo de tecnificación. Del mismo modo, la planta de coca no era desconocida para los primeros habitantes que colonizaron estos territorios, existen evidencias desde las narraciones de sus habitantes que dan cuenta que durante los primeros años esta planta cumplía funciones eminentemente culturales a través de su uso tradicional como mambe, práctica que nace de masticar "la combinación de la hoja de coca tostada y pulverizada y de la ceniza de yarumo. Esta última tiene como función liberar el alcaloide de la planta para dejar al descubierto sus propiedades. Una vez obtenido se combina con una pasta de tabaco denominada ambil" (Rodríguez, 2010, párr. 2).

Ya en la década del 70 los cultivos de coca adquieren un interés ilícito por sus importantes ganancias económicas, siendo el sur de Colombia, principalmente el departamento del Caquetá en donde se iniciaron las plantaciones de coca con fines de extracción de alcaloides (Cano, 2002 citado por Castaño, Bernal, Marín y Ramírez, 2003). Para el caso específico del departamento del Cauca, la caída de los precios del café tras la ruptura del pacto de cuotas en la década del 80, generó condiciones para el surgimiento de una vasta suma de mano de obra desempleada que tuvo que regresar a sus lugares de origen.

El pacto de cuotas fue un acuerdo internacional suscrito entre los países productores de café y los compradores, en el cual se fijaron unas cuotas de exportación del grano distribuidas trimestralmente para controlar los períodos de excesos de producción y de esta manera regular los precios garantizando un mejor ingreso para los productores. El pacto estuvo acompañado de la realización de una importante campaña publicitaria dirigida a incentivar en consumo de café a nivel mundial.

Los cultivos de coca iniciaron su expansión no precisamente en aquellos territorios dedicados al cultivo del café, sino en aquellos departamentos en donde la debilidad institucional y condiciones climáticas adecuadas propiciaban ventajas comparativas para el cultivo (Daza, 2016). De esta manera, zonas apartadas de los centros 
urbanos como el caso de El Plateado se constituyeron en lugares propicios para la implementación y expansión de las plantaciones de coca.

Con la llegada y expansión de los cultivos de coca, a nivel local se fue creando un modelo económico que terminó por reemplazar por completo la anterior base productiva y a su vez las relaciones de convivencia en la comunidad. Frente a este último aspecto, con el desarrollo de una economía del narcotráfico llegaron también los grupos armados pertenecientes a las Fuerzas Revolucionarias de Colombia (FARC-EP), y posteriormente guerrillas pertenecientes al Ejército de Liberación Nacional (ELN). El aparato militar del Estado que también ha hecho presencia en la zona generó un escenario de tensión y violencia frente al control territorial por la disputa de poderes entre los actores armados con acción en el territorio. De igual forma, con la presencia de grupos paramilitares en la región aumentaron también los casos de violación de los derechos humanos; las torturas, desapariciones y muertes, fueron sucesos que se incrementaron en el municipio de Argelia finalizada la década del 90, y que desde luego terminaron afectando a los habitantes del corregimiento, situación que condujo a un gran periodo de crisis en donde ser o vivir en El Plateado o corregimientos aledaños representó vulnerabilidad y riesgo, puesto que significó ser colaboradores de los grupos guerrilleros, excusa que usaron los grupos paramilitares para cometer sus torturas y muertes, situación que parece repetirse luego de la salida de los miembros de las FARC-EP del territorio hacia las zonas de concentración veredal, en el marco de los actuales acuerdos de paz entre el Estado colombiano y este grupo insurgente.

No hay que negar tampoco que con la implementación de la política antidrogas en Colombia se generaron una serie de impactos en los territorios, los procesos de militarización y control territorial bajo el discurso de lucha contra el comunismo y los procesos de aspersión con glifosato para evitar la expansión de los cultivos de coca, también generaron profundas secuelas en las comunidades afectadas, no solo desencadenando procesos de confrontación armada, sino también destruyendo los cultivos que garantizan el sustento económico. A su vez, se generaron desplazamientos de la población civil y más grave aún, muertes que, según los pobladores, pueden tener como causa intoxicaciones por la aspersión de glifosato en el territorio. 
De igual manera, no se puede desconocer que el municipio de Argelia, al igual que varios municipios del suroccidente del Cauca, desde hace varios años se encuentra en la mirada de grandes trasnacionales mineras, situación que preocupa a los habitantes, ya que existe el riesgo de que en estas zonas se desarrollen grandes proyectos mineroenergéticos, situación en la cual la población civil y los ecosistemas locales terminarán siendo los grandes afectados. Es bajo la radiografía anterior que se enmarcan las páginas siguientes, en donde se relata desde la voz de quienes han vivido en el corregimiento, esos momentos de violencia que han tenido que padecer en medio de una economía que gira alrededor de lo ilícito.

De esta manera, el documento aborda como punto de partida una breve mirada a los cultivos de coca desde un enfoque neoinstitucionalista, desde el cual se intenta explicar en parte la existencia y expansión de los cultivos de coca con fines ilícitos; seguido, se presenta el abordaje metodológico bajo el cual se desarrolló la investigación; finalmente se presentan evidencias de la violencia desarrollada en el territorio como resultado de la presencia de distinto actores armados, como también los efectos de las fumigaciones aéreas en el marco de la política de lucha contra las drogas aplicada en el territorio. Otro asunto que interesa es la latente amenaza frente a los intereses de grandes trasnacionales mineras en el territorio por los recursos mineros bajo el auspicio de la actual política minera nacional, realidad a la cual se le dedica la última parte del documento.

\section{LOS CULTIVOS DE COCA Y LA VIOLENCIA, UNA APROXIMACIÓN DESDE EL NEOINSTITUCIONALISMO}

Esta sección no tiene por propósito hacer un análisis detallado y riguroso de las diferentes posturas y debates surgidos alrededor del neoinstitucionalismo como corriente teórica, solo tiene como objeto establecer algunos puntos de análisis para comprender el desarrollo de los cultivos de uso ilícito, como el resultado de la inestabilidad e ineficiencia institucional características de Estados como el colombiano. 
El neoinstitucionalismo surge a finales del siglo XIX y principios del siglo XX, y desde su postura teórica reconoce la importancia que cumplen las instituciones en las diferentes dinámicas sociales y económicas dirigidas a generar procesos de desarrollo de los Estados-nación. Siendo las instituciones su matriz bajo la cual gira su corriente de pensamiento, es importante dar un vistazo rápido al concepto de institución propuesto por algunos autores. Para el nobel economista North (1993) citado por Urbano, Díaz y Hernández (2007), "las instituciones son las reglas del juego en una sociedad o, más formalmente, son las limitaciones ideadas por el hombre que dan forma a la interacción humana” (p. 8), y Kalmanovich (1999) agrega a las instituciones como las reglas "que encausan el desarrollo económico, pero son también un resultado histórico, [...] están influidas por las ideologías legales y religiosas que dan lugar a una ética pública” (p. 1).

Como lo menciona Velázquez (2008) citado por Benavidez (2012), las instituciones pueden ser de carácter formal o informal. Las primeras definidas por un conjunto de normas, leyes y demás escritos que hacen parte del derecho positivo; las segundas responden más a códigos de conducta que hacen parte del derecho consuetudinario, construido a partir de una serie de normas culturales que perduran o mutan en el tiempo. Para Stavenhagen (s.f.), citado por Soria (s.f.), lo que caracteriza al derecho consuetudinario es:

\footnotetext{
Precisamente que se trata de un conjunto de costumbres reconocidas y compartidas por una colectividad (comunidad, pueblo, tribu, grupo étnico o religioso, etc.), a diferencia de leyes escritas que emanan de una autoridad política constituida y, cuya aplicación está en manos de esta autoridad, es decir, generalmente el Estado. (p. 107)
}

En el caso de las instituciones de carácter formal, el conjunto de normas y leyes que hacen parte de las reglamentaciones del Estado, a su vez, el cúmulo de instituciones que deben brindar las condiciones y garantías para la intermediación entre los intereses de los gobiernos y los intereses de las comunidades presentan distanciamientos que generan estados de crisis. 
Las instituciones formales al estar circunscritas dentro del conjunto normativo creado por los individuos para regular y coordinar las dinámicas de orden económico, social y político, adquieren una connotación de obligatorio cumplimiento, requiriendo del uso de la coerción y la fuerza para hacerlas cumplir (Daza, 2016). En este sentido, los cultivos de coca al estar dentro de una categoría de lo ilícito, requieren de la acción institucional del Estado para evitar el tráfico de drogas, situación que para el caso colombiano no ha tenido los resultados que se esperaban en el marco de la aplicación de la política de lucha contra las drogas. Tal como lo expresa Daza (2016):

Las acciones tendientes a prevenir y evitar las prácticas de la economía del narcotráfico no han surtido sus efectos, en la medida en que las instituciones del Estado colombiano no hicieron presencia total a lo largo y ancho del país, y adicional a esto, sus políticas de intervención fueron de carácter coercitivo contra quienes infringían las normas, sin que brindaran a la sociedad las posibilidades económicas y sociales, dando lugar a la dedicación de cultivos tradicionales a la siembra de cultivos ilícitos. (p. 38)

Un aspecto fundamental para el buen funcionamiento institucional es la existencia de unos derechos de propiedad bien definidos, los cuales, de acuerdo con Eggertsson (1995) citado por Rivera (2013), pueden considerarse como "un método mediante el cual se confiere a los individuos la potestad de seleccionar, para bienes específicos, cualquier uso entre todo un conjunto de usos posibles no prohibidos" (p. 194). En Colombia, el despojo histórico de tierras, y a su vez la concentración de la propiedad en grandes terratenientes que dedican áreas cultivables a grandes proyectos agroindustriales como caña de azúcar, palma de aceite o fomento de la ganadería extensiva, coloca en una situación de crisis la claridad de unos derechos de propiedad bien definidos, en especial para las comunidades rurales. Como lo menciona la Comisión Nacional de Reparación y Reconciliación. Grupo de Memoria Histórica (2009):

El despojo de tierras y bienes suele conseguirse regularmente a través del uso de la violencia física sobre las poblaciones rurales, lo que por lo general produce su desplazamiento forzado y el abandono del territorio, el cual queda a merced del actor armado. Sin embargo, en múltiples casos, esa apropiación 
física y violenta por la vía armada, aparece acompañada adicionalmente de la utilización de alguna figura jurídica con la que el perpetrador pretende adquirir formalmente los derechos sobre la tierra para disponer legal o ilegalmente de ella. (p. 36)

La propiedad de la tierra como factor de disputa histórico, ha sido uno de los elementos generadores de los procesos de subversión y éxodo rural. Mientras grandes élites del país se han apropiado de las mejores tierras de la nación, muchos de los habitantes de la ruralidad colombiana han sido desplazados a las zonas de montañas, en donde la presencia institucional del Estado y la garantía del cumplimiento normativo no se han dado de manera eficiente.

El mundo rural colombiano presenta muchas restricciones en torno a la claridad frente a la propiedad de la tierra, lo que no permite que se haga un uso y usufructo eficiente de la misma por parte de muchos campesinos, al igual que se presentan dificultades para transferir los derechos de propiedad a otro individuo. Como lo señala Daza (2016), quizá una de las tantas causantes a la restricción de los derechos de propiedad sobre el suelo radica en la histórica existencia de grupos al margen de la ley. En el caso de las zonas con cultivos de uso ilícito, la presencia de diferentes actores armados impone una serie de restricciones como el cobro de impuestos, restricciones de movilidad, entre otros aspectos. Situación que dificulta directa o indirectamente los derechos de sobre la tierra. El Estado, además como garante de derechos y en su ejercicio legítimo del uso de la fuerza para la garantía de condiciones suficientes de derechos de propiedad en las zonas rurales, no logró su cometido.

Es evidente el no cumplimiento a cabalidad de esta función, porque existen grupos diferentes a los estatales, quien hacen las veces de fuerza legítima, además de tener la capacidad de controlar extensos territorios, de hacer cumplir otro tipo de reglas, de proporcionar seguridad, etc., de tal forma, reemplaza en cierta forma la fuerza legítima del Estado. (Daza, 2016, p. 43)

Los intereses económicos que se trazan en los territorios impulsaron de alguna manera la simbiosis entre el narcotráfico y la presencia de grupos armados al margen 
de la ley en aquellos lugares en los cuales el Estado no fue capaz de proporcionar las garantías suficientes para el desarrollo de economías en el marco de lo lícito. En el caso concreto del corregimiento de El Plateado, la aparición del octavo frente de las FARC-EP tuvo coincidencia con los años en que aparecieron los cultivos de coca en el marco de lo ilícito, posteriormente, la presencia de las guerrillas del ELN y grupos paramilitares generaron dinámicas de un crudo conflicto tras intereses por el control del territorio. Estos últimos no solo como el resultado de la precariedad del Estado en cuando a su presencia institucional y regulación normativa, sino como el resultado de otros factores que se manifiestan en el Informe de Desarrollo Humano, Colombia rural, razones para la esperanza del PNUD (2011):

El paramilitarismo que surgió durante los primeros años de la década de 1980, no fue resultado solamente de la ausencia o precariedad del Estado o de un vacío ostensible de poder. Factores como la debilidad estatal en la regulación social de conflictos, la ambivalencia de los individuos frente a la autoridad del Estado, la existencia de una porción importante de población fuera de la institucionalidad oficial y los incentivos para quienes delinquían por los bajos riesgos de ser castigados por la ley también tuvieron su cuota en el surgimiento del problema. (p. 227)

Un aspecto adicional que menciona Daza (2016) tiene que ver con los tipos de gobiernos. El desarrollo de las regiones estará en estrecha relación con sus intereses y toda la política institucional responderá a unos patrones de desarrollo ya definidos. Por ejemplo, la política minera implementada desde el gobierno de Álvaro Uribe Vélez, dio paso para que en muchas regiones de Colombia grandes trasnacionales mineras colocaran sus ojos, y el Estado a través de su aparato institucional legitimara sus acciones a partir de la concesión de títulos mineros a lo largo y ancho del país, situación de la cual el municipio de Argelia no ha sido la excepción.

En este sentido, es posible afirmar que la debilidad institucional y normativa del Estado colombiano no ha brindado las garantías suficientes para el desarrollo de economías campesinas en el marco de la legalidad, la ausencia institucional propició un escenario para la germinación y desarrollo de las economías del narcotráfico a 
partir de la implementación de cultivos de uso ilícito. El uso de la fuerza como mecanismo de coerción del Estado tampoco han sido efectivos, el fracaso de una política de lucha y combate de las drogas es un hecho evidente, al igual que el desarrollo de otras relaciones entre las comunidades y los grupos armados se hace evidente frente a una situación de crisis social, en donde parte de los actores armados suplieron la falta de presencia institucional del Estado en las regiones.

\section{Aspectos METOdológicos}

La investigación corresponde a la tipología de estudios de carácter cualitativo, en el cual la revisión documental, la observación participante, el diálogo con informantes clave, los relatos de vida y los grupos de discusión, fueron herramientas que se convirtieron en importantes elementos para describir el desarrollo sociohistórico derivado de la presencia de cultivos de uso ilícito en el corregimiento de El Plateado. En principio se acudió a la revisión documental de textos y archivos periodísticos, en los cuales se buscó información relacionada con el desarrollo de los cultivos de coca en Colombia para ubicar los principales sucesos históricos que incidieron en su expansión hacia el suroccidente del país, y en el caso concreto de la investigación, su llegada al corregimiento de El Plateado. Luego se indagó en campo a informantes clave que han vivido por varios años y conocen muy bien la historia de la llegada y expansión de los cultivos de coca en la localidad, y a su vez han tenido que vivir y padecer los momentos de violencia desarrollados como resultado de las nuevas dinámicas socioeconómicas surgidas con la llegada de los cultivos de coca. La "bola de nieve" fue una estrategia valiosa para identificar a las personas con quienes se establecieron los diálogos, caracterizándose estos por ser líderes comunitarios, además, por haber vivido durante muchos años en el corregimiento, factor que le da un margen de confiabilidad a sus relatos, ya que muchas de sus narrativas son el reflejo de lo que han tenido que vivir dentro del territorio.

Se entrevistó a un total de 6 personas con las cuales se acordaron, de manera concertada, los momentos de encuentro y se realizaron dos talleres participativos para la reconstrucción de la memoria colectiva, en el cual participaron jóvenes y 
adultos pertenecientes al programa 3011 (hace referencia a la educación para jóvenes y adultos reglamentada bajo el decreto 3011 del 19 de diciembre de 1997) de la Institución Educativa Técnica Miguel Zapata ubicada localizada en el corregimiento de El Plateado, municipio de Argelia. El relato de vida de dos habitantes de la comunidad también fueron claves para comprender desde sus narrativas el desarrollo histórico de los cultivos de coca y los periodos de violencia en el escenario local. La información obtenida fue contrastada con archivos periodísticos para tener una radiografía más completa de la dinámica sociohistórica desarrollada en el marco de lo ilícito en el corregimiento.

\section{LOS CULTIVOS DE COCA Y LA VIOLENCIA GUERRILLERA en el corregimiento de El Plateado, el resultado DE UNA CRISIS INSTITUCIONAL}

El corregimiento de El Plateado para muchos es visto desde afuera como un lugar peligroso dentro de las entrańas de las montañas del departamento del Cauca, imagen que se ha generado como producto de los diferentes enfrentamientos armados que durante varios años han afectado de manera permanente a la población, generando una profunda crisis social y humanitaria. En una columna del periódico El Espectador, Molano (2012) presenta una pequeńa radiografía del conflicto entre la población civil y el aparato armado del Estado que hizo presencia dentro del caserío del corregimiento durante el periodo 2008-2010.

El Plateado ha progresado si así puede llamarse al desarrollo del comercio a costa de arrasar la selva para sembrar coca que es la fuente de la que se nutren los negocios, incluyendo la precaria ganadería local. En el corregimiento, la Policía fue obligada a salir por presión de la población, respaldada por las FARC; una presión determinada por la guerra en la que convergen intereses de la población civil con la estrategia política y militar de la subversión. (párr. 2)

Los cultivos de coca no solo trajeron un incremento sustancial de los ingresos económicos para los habitantes frente a un escenario en el cual el Estado no brindó 
las garantías suficientes para el desarrollo de economías lícitas, sino que también significaron el incremento de los niveles de violencia en el plano local. Una vez que aparecieron las primeras plantaciones también llegaron al territorio inicialmente grupos armados pertenecientes a las FARC-EP, y luego aquellos que hacen parte de las filas del ELN. Desde luego que el Estado también ha hecho presencia en los últimos ańos con su aparato militar, no se puede desconocer también los momentos de la arremetida de grupos paramilitares en la zona, fenómeno que parece reavivarse nuevamente con la persecución, amenazas y muerte de varios líderes sociales en lo corrido del año 2016 y principios del 2017.

Si bien es cierto que durante el año 2016, como resultado de los acuerdos de cese al fuego derivados de los diálogos de paz y de las acciones de la comunidad a través de la expulsión de las fuerzas militares de su territorio, se generó un ambiente de mayor tranquilidad para la población civil, es innegable que en la memoria y en los cuerpos de los habitantes quedan cuantiosos recuerdos y daños que tal vez nunca serán borrados ni reparados. Muchos rememoran momentos en que se vivió una violencia desenfrenada en la cual llegar al territorio sin ningún acompańamiento de los lugareños era comprar un pase directo a la muerte, o instantes en los cuales toda una generación de jóvenes bajo la convicción de lograr una transformación radical del poder estatal a través del uso de las armas, terminaron cediendo sus vidas en el campo de batalla de una guerra que financian aquellos que no están en medio del fuego cruzado.

Pese a que a nivel local no existen referentes específicos frente al número de víctimas del conflicto armado, es posible hacer una radiografía general a partir de las denuncias presentados en el Registro Único de Víctimas (RUV), en el cual reposan algunos datos para el municipio de Argelia. Hay que advertir que los casos reportados pueden no ser exactos, ya que existe la posibilidad de que se hayan denunciado eventos similares en ańos diferentes, sin embargo, los reportes permiten tener una idea general de los efectos que ha tenido la guerra a nivel municipal a través de acciones como actos terroristas, amenazas, desaparición forzada, desplazamiento forzado y homicidios durante finales de la década del 70 y década del 90. 
Figura 1. Reporte de habitantes del municipio de Argelia afectados por el conflicto social y armado entre finales de la década del 70 y los 90

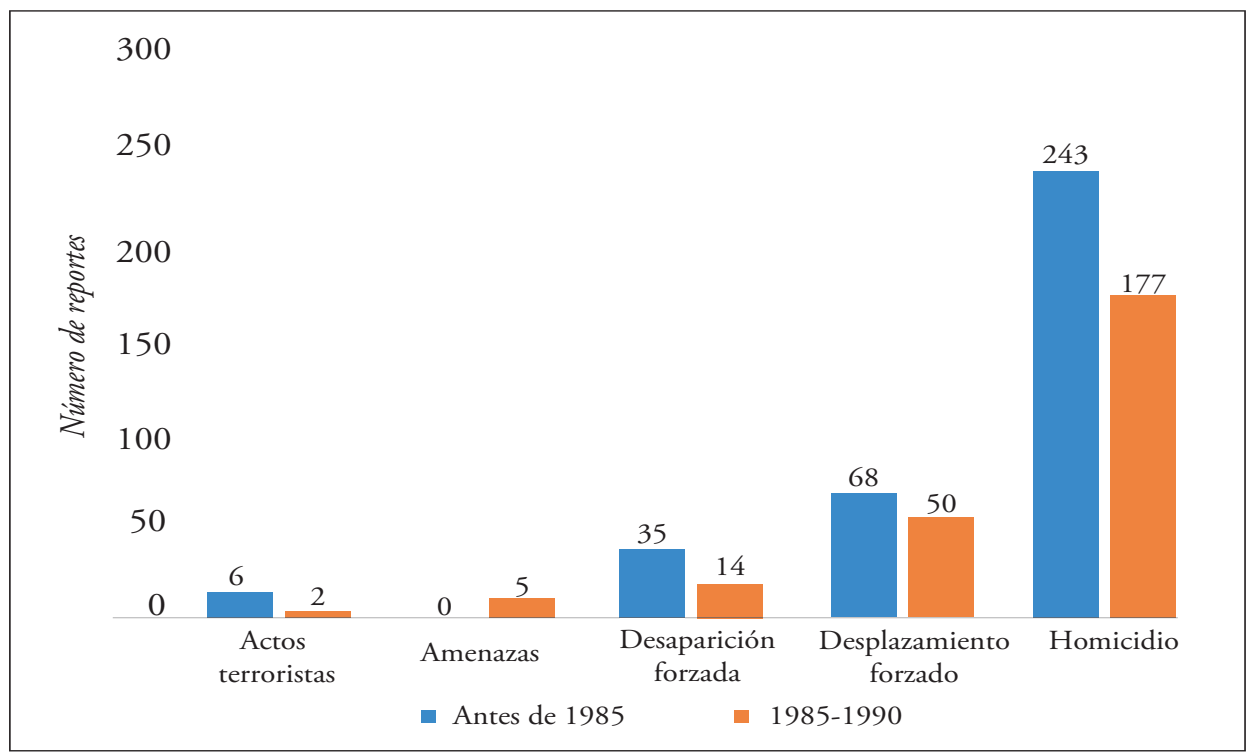

Fuente: elaboración propia a partir de datos disponibles en el Registro Único de Víctimas (2016)

Con base en la figura anterior, puede observarse que entre finales de la década del 70 y durante la década del 80 hubo un número significativo de víctimas por el conflicto armado, siendo más numerosos los casos reportados por homicidios, desplazamiento forzado y desaparición forzada, lo cual coincide con las relatos de habitantes, quienes mencionan que tras la llegada de los cultivos de coca también se generó una oleada de violencia en la zona, siendo más aguda en corregimientos como El Mango y El Plateado. Pese a ello, son cifras que no se equiparan a los reportes presentados para municipios como Almaguer, perteneciente al macizo colombiano, que para el mismo periodo presenta un total de reportes dentro de los hechos victimizantes señalados de 1.088 casos, frente a los 600 casos reportados en el municipio de Argelia, evidenciando que en otras zonas del Cauca la violencia vivida durante este periodo fue más aguda. 
También hay que mencionar que a partir del procesamiento de hojas de coca con fines ilícitos las condiciones económicas de muchas personas mejoraron sustancialmente, sin embargo, para otras significó la pérdida de familiares, amigos o quizá personas con las que nunca dialogaron, pero que las vieron caer en medio de las balas que se cruzaban por las calles del caserío de la población, o aquellos que eran llevados hasta la orilla de los ríos para darles su sentencia final y luego ser arrojados a las aguas. "Con la plata que dejaba la coca se rehízo la guerra: fue la munición de todo fusil oficial, paraoficial o insurrecto [...] tiempos de huida, de engarruñamiento, de soledad. Años de seguridad para matar y comer del muerto" (Molano, 2015).

Desde la memoria se recuerdan sucesos de la época, en la cual la muerte deambulaba por las calles y veredas del corregimiento a plena luz del día y también en medio de la oscuridad de la noche, tal como lo expresa una docente que vivió gran parte de su vida en la localidad:

Cuando yo llegué me hicieron reunión [FARC-EP] porque pensaban que yo era una infiltrada de la ley [...], antes que yo me había traído unas fotocopias de mi nombramiento. En ese tiempo había inspector, pero a nosotros nos daba mucho miedo al principio; después se nos fue pasando porque uno no se metía con nadie, uno hacía su trabajo y ya [...], pero a nosotros los profesores nos tocó ver muchas matanzas, ellos [FARC-EP] no permitían que entrara gente extraña. Según la gente, ese río dizque era lleno de muertos, ahora, cuando viajábamos de allá en donde nos dejaba el carro hasta acá encontrábamos en el camino los charcos de sangre y las trillas por donde los arrastraban hasta el río [...], en ese tiempo hubo muchas muertes. También al frente de las discotecas [... ¡ Unas feítas que habían!, llegaban y los sacaban afuera y tas, tas, tas. (Institución Educativa Técnica Miguel Zapata, 2016)

En el relato se hace referencia a la presencia de guerrilleros pertenecientes al octavo frente de las FARC-EP quienes ejercían control sobre el territorio y determinaban quién podía o no ingresar a la zona. Además, no era un secreto que los campesinos sentían cierta simpatía por la presencia guerrillera, tal como se evidencia en el siguiente relato: 
En esa época comandaba en la zona el octavo frente de las FARC, ahora es el 60 frente. Uno se atemorizaba cuando llegaban, sabían llegar al amanecer donde ahora es el parque a echar bala al aire y a gritar consignas [...]. Vivan las Fuerzas Revolucionarias de Colombia, ¡Vivan! La gente les colaboraba harto, cuando veían que llegaban corrían a darles en ese tiempo agua de royal [...], los campesinos en ese tiempo estaban muy motivados con ellos, ellos eran la ley acá [...], la gente los protegía bastante, cada quince días se hacían festivales para el Partido Comunista. (Institución Educativa Técnica Miguel Zapata, 2016)

En el relato anterior se evidencia cómo ante la poca presencia institucional, las FARC se convirtieron en una organización que suplió en gran parte el abandono del Estado en el territorio, hecho bajo el cual los campesinos vivieron bajo su complicidad y bajo la garantía de la seguridad brindada por este actor armado.

Durante las primeras décadas después de aparecer la coca con fines ilícitos en la zona, las muertes no dieron tregua. Muchas personas perdieron sus vidas puesto que solo bastaba ser un desconocido para recibir su sentencia final. La muerte para muchos habitantes se convirtió en algo normal, para otros, con el paso del tiempo abrió cierta sensibilidad que permitió que poco a poco los ajusticiamientos fueran cediendo paso a otras prácticas en donde ya no era la guerrilla quien determinaba los castigos, sino que fue la comunidad quien empezó a decidir qué hacer con las personas que por alguna razón eran juzgadas. A continuación el relato de un exdocente:

Ya después hacían reuniones con la comunidad la guerrilla cuando cogían a alguien que había hecho algo malo [...], lo colocaban al frente y decían, ¿qué pide la comunidad que se haga con esta persona? [...], muchos decían: ique lo maten, que lo maten! [...], ya estaba eso metido en la cabeza. Ya vino a cambiar esto mucho después cuando la guerrilla decía qué quieren, que lo fusilemos, lo desterremos o le ponemos una sanción; ya a la gente le fue cambiando un poco la mentalidad, ique lo destierren decían! [...]. Una vez habían cogido a un señor de edad que había matado a otro y lo sacaron para que la comunidad decidiera, había un poco de niños sentados allí al lado y le 
dijeron que lo desterraran porque esos niños se prendieron de él y lloraban para que no lo fueran a matar [...], le dieron una hora para que se fuera del pueblo. (Institución Educativa Técnica Miguel Zapata, 2016)

También en los relatos se menciona que hubo toda una generación de niños y jóvenes que se convirtieron en simpatizantes de las guerrillas, y luego se unieron a la lucha armada en la cual perdieron sus vidas. Las escuelas eran no solo el escenario donde los docentes intentaban educar a los niños y jóvenes, también fue el espacio predilecto en donde los guerrilleros hacían sus campañas de adoctrinamiento. Si bien no obligaban a nadie a unirse a sus filas armadas, finalmente lograban seducir e incorporar a los jóvenes en su lucha.

En ese tiempo yo llegué a tener unos muchachos, ¿en ese tiempo sabe ¿qué era lo que más les inclinaba? [...], irse para la guerrilla, eso sí, hasta unas niñas que ya están bajo tierra, un niño que desde primerito ¡que yo quiero ser guerrillero! Uno los motivaba [...], el problema en ese tiempo a los niñitos, ¿por qué les llenaban el cerebro? [...] porque ellos llegaban a la escuela en horas de descanso, se sentaban en el piso y los llamaban y ellos les hacían ruedo para ver cómo armaban y desarmaban esas pistolas, cómo les colocaban los tiros [...], no sé qué les dirían, pero ellos no alcanzaban ni a terminar el tercero y ya se iban para la guerrilla [...], niños, niños... iy los mataron! (Institución Educativa Técnica Miguel Zapata, 2016)

\section{ViolenCia Militar DEL EsTado COLOMBIANO Y LA AMENAZA PARAMILITAR, UN REFLEJO DE LA PÉRDIDA DEL CONTROL EN EL USO DE LA FUERZA}

Entrada la década del 90 a través de la política antidrogas, Colombia se convirtió en el país mayor receptor de ayuda militar estadounidense, pero a su vez, se constituyó en la nación con mayores casos de violaciones a los derechos humanos. "La relación bélica alcanzó su cúspide en 1999 cuando Colombia [...] se convirtió en el país oficial predilecto de Estados Unidos para la guerra a través del afamado Plan Colombia” 
(Bustamante, 2016). Esta situación trajo como consecuencias desplazamiento forzado de poblaciones, desapariciones y ejecuciones de civiles presentados como muertos en combate por las fuerzas militares del Estado, ejecuciones de civiles por grupos paramilitares bajo la complicidad estatal, despojo de tierras, en general, violación a los derechos humanos de las comunidades, realidad de la cual el municipio de Argelia tampoco pudo escapar.

Según el Registro Único de Víctimas (2016) en comparación con la década del 80, durante los 90 y posteriormente a partir de la década siguiente, se incrementaron en el municipio de Argelia las denuncias de afectados por actos terroristas, desaparición forzada, desplazamiento forzado, homicidios, minas antipersona, entre otros casos. Situación en la cual muchos de los reportes corresponden a los casos de violencia vividas como producto de la confrontación armada entre guerrilleros de las FARCEP y militares del Estado colombiano en corregimientos como El Mango y El Plateado, sin desconocer también que existen casos en donde se ve involucrada la acción de grupos paramilitares en la región.

A partir del año 2000 el conflicto se empezó a agudizar aún más, lo cual tiene estrecha relación con la implementación de la política del Plan Colombia y el discurso de lucha contra el enemigo interno a partir de la aplicación de la política de Seguridad Democrática del gobierno de Álvaro Uribe Vélez en la región. El incremento de los reportes de casos de personas desplazadas y también las tasas de homicidios desde el año 2000 fueron aspectos que develan los efectos del incremento del conflicto armado en la zona. 
Figura 2. Número de habitantes del municipio de Argelia afectados por el conflicto social y armado en el periodo comprendido entre los años 1991 y 2015

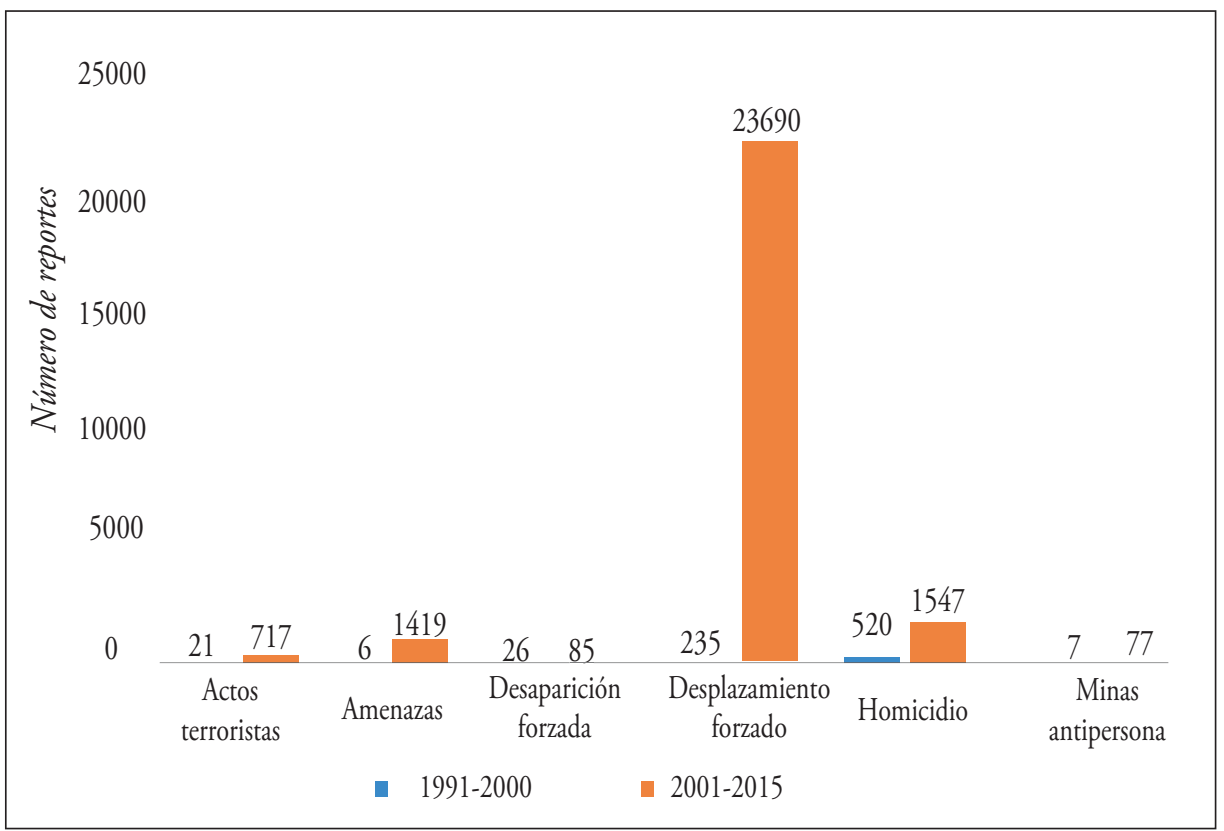

La larga lista de afectaciones empeoró aún más frente a la disputa militar por el control territorial entre las guerrillas de las FARC-EP y el ELN a nivel local, dividiendo el territorio en dos partes, cada una controlada por distintas fuerzas armadas.

En el año 2007 las FARC y el ELN chocaron entre sí por el control de los cultivos de coca en los municipios de El Tambo, Patía y Argelia. A los golpes que les dio el ELN a las FARCles cayeron tres operaciones militares que duraron alrededor de seis meses y fueron conocidas como Espada 1, Espada 2 y Espada 3. Producto de esos dos frentes de batalla, los Frentes 8 y 60 de las FARC perdieron a muchos de sus integrantes, bien fuera caídos en combate o por deserciones en 
sus filas. Para protegerse, se desplazaron de la zona de cordillera hacia la Costa Pacífica. El espacio que dejaron fue rápidamente copado por una alianza entre Los Rastrojos y guerrilleros del ELN. (Verdadabierta.com, 2014)

Bajo esta situación, en la disputa por el control territorial entre las FARC-EP y el ELN se repartieron el botín producto de los impuestos cobrados al narcotráfico en la zona. Pero no solo fue la presencia armada guerrillera que estableció un nuevo orden por el control territorial local, también fue la presencia armada militar del Estado y la amenaza paramilitar las que profundizaron aún más la crisis social y humanitaria para los pobladores del municipio de Argelia. De acuerdo con relatos de algunos pobladores, desde el ańo 2006 la presencia paramilitar ya había llegado al municipio y su incursión se aproximaba a la población de El Plateado, situación que fundó terror y miedo en los habitantes y posteriormente dejó víctimas directas en la comunidad.

El 3 de marzo de 2007, un grupo de hombres armados denominado Águilas Negras llegó a la vereda El Plateado [...] y asesinó a tres personas luego de torturarlas. Después, los hombres armados asesinaron a una mujer, madre de cuatro nińos, dentro de su casa en la misma vereda. Los hombres armados lanzaron los cuerpos de las tres primeras víctimas al río San Juan de Micay, de donde días después campesinos de la vereda los rescataron. Los cadáveres estaban atados de pies y manos, con las orejas cortadas, degollados y abiertos desde el cuello hasta el abdomen. (Rutas del conflicto, 2007)

Para el año 2010 el grupo paramilitar que hacía presencia en la zona recibió el más duro golpe: 20 de sus integrantes fueron asesinados provocando su desplazamiento hacia la costa pacífica, y luego en el 2011 tras una nueva avanzada guerrillera de las FARC, los paramilitares fueron desplazados totalmente de la región. Una habitante de la zona narra algunas situaciones como las siguientes:

Los paramilitares llegaron hasta Puerto Rico, ¡ahí sí que nos daba miedo oiga! [...], yo hablé con el comandante, en ese tiempo era uno que le decían Grillo [...], yo le dije que no se fuera a ir de aquí porque los paramilitares han dicho 
que van a venir y nos van a sacar como guaguas de aquí, dizque nos va a echar gasolina y nos van a prender candela [...]. Yo una vez miré a unos paramilitares aquí, estaban cobrándole el impuesto a uno de los que trabajaba en El Pinche, se habían metido por Santa Clara y otros por Puerto Rico. A los de Santa Clara les hicieron carnizada, ¡mataron un poco por el aire! Pensaron que eran guerrilleros y los fumigó el helicóptero y habían sido paramilitares [...]. Los paramilitares estuvieron harto tiempo en Puerto Rico y en Sinaí con esos chalecos negros para allá y para acá. Acá fue porque les hicieron una matanza grande y si no, jjuuuumm! [...]. De Argelia para acá abajo también les hicieron una matanza fea, mataron a unos que habían estado pidiendo remesa en Argelia, después los siguieron hasta donde tenían los cambuches y también les dieron, por eso fue que se fueron. Eso era cosa grave, en el Estrecho todo el que era de El Plateado lo bajaban de los carros y lo mataban. Una vez me llevé un susto tremendo, en esa época eran unos buses amarillos grandes de Coomotoristas, no había camionetas todavía y eso a don Agustín le mataron un hijo dizque porque era colaborador de la guerrilla, al él lo bajaron que venía de Cali y lo echaron en un taxi por allá para una vereda de Remolinos [...], un día había uno que fue farucho, fue raspachín primero, trabajador de los de los de por aquí y después se metió con la guerrilla. De la guerrilla se salió y se metió con los paramilitares. ¡Le decían pecho de pato! Y yo lo encontré varias veces en los retenes de los paramilitares que hacían de Balboa para acá arriba. Un día me lo encontré [...]. A uno le daba mucho miedo porque yo lo conocía y él también me conocía, sabía de dónde venía. (Relato de habitante de la comunidad)

De acuerdo con este relato, durante la arremetida paramilitar en la zona, ser o vivir en El Plateado se convirtió también en una señal de muerte para las personas que se desplazaban desde el corregimiento a otras localidades, como la ciudad de Popayán capital del Cauca. Vivir en El Plateado adquirió el significado de ser colaborador o en su defecto pertenecer a los grupos armados guerrilleros, lógica bajo la cual el terror paramilitar cobró también la vida de muchas personas de la región. Y es que no era para más, con la presencia paramilitar en la zona la muerte cabalgaba al lado de su mano armada, infundado terror con las desapariciones permanentes de líderes 
comunitarios y torturas sistemáticas desarrolladas en cualquier hora del día y en cualquier lugar del municipio.

Durante estos años seudónimos como alias El Zarco, Comandante Blanco, El Tanque, El Pastuso, Bray, Sangre, entre otros, se convirtieron en el terror que azotó en el municipio de Argelia con arremetidas fuertes en corregimientos como El Mango y Sinaí, todo bajo la misma complicidad de los militares que hacían presencia en la zona. Las amenazas, las torturas, violaciones, desapariciones, desplazamiento y desmembramiento de cuerpos fueron hechos imborrables que quedaron grabados en las memorias como muestra de una política de control y ocupación territorial.

Es cierto también que durante el periodo de gobierno de Álvaro Uribe Vélez bajo la política de Seguridad Democrática se incrementó el pie de fuerza armado del Estado en todos los rincones del país bajo la pretensión de reducir en combate a los grupos guerrilleros, situación que estuvo acompañada del incremento de la presencia paramilitar. Luego de sus dos periodos de gobierno, quedó como saldo una larga lista de ejecuciones extrajudiciales y una gran masa de campesinos desplazados de sus campos para insertarse en las ciudades en condiciones de miseria.

Otra situación que agudizo aún más el conflicto en la zona fue que bajo la lógica de la confrontación armada, desde el gobierno central se ordenó la instalación de bases militares y estaciones de policía en lugares estratégicos del país, entre las cuales el corregimiento de El Plateado terminaría siendo víctima de los continuos enfrentamientos armados entre las guerrillas y militares. Durante los años 2008 a 2010 la Policía ocupó el espacio público de la caseta comunal del corregimiento, poniendo en peligro la vida de la población civil, situación que condujo a que finalmente la comunidad se organizara y ejerciera presión para que la Policía se retirara del lugar. Molano (2012) describe los hechos sucedidos de la siguiente manera:

El litigio se originó en la utilización de la caseta comunal por parte de la Policía sin autorización de la junta y con grave y notorio deterioro de la edificación [...]. La fuerza pública, que permaneció en la caseta entre 2008 y 2010, construyó en 
ella trincheras con sacos de arena, instaló dormitorios y puesto de mando, así como usó una superficie para jugar fútbol de salón [...]. (párr. 3)

La tensión crecía a medida que, según denuncias puestas ante la Defensoría, los uniformados atropellaban a la gente, la drogadicción aumentaba, los robos se hacían a la luz del día y se amenazaba con el regreso de los paramilitares. En enero de 2011 el Ejército se instaló en la concentración escolar Miguel Zapata y montó retenes a las entradas y salidas del pueblo donde, argumentan los vecinos, todo era considerado ilegal: las remesas de comida, las gallinas, los plásticos, los abonos, todo aquello que pudiera estar asociado con el cultivo de la coca o servir de medio logístico para la guerrilla. (párr. 4)

Para muchos de los habitantes de este lugar, el conflicto armado se convirtió con el tiempo en algo natural. En momentos de enfrentamientos armados fue común escuchar expresiones como "tranquilo que eso no pasa nada, son unos tiritos nada más”, o también era natural que cuando llegaban los helicópteros a la zona, muchas personas salieran a las calles del corregimiento a esperar el instante en que desde cualquier esquina los subversivos lograran derribar la aeronave. Los efectos del conflicto han quedado grabados en la memoria de aquellos que han tenido que perder familiares y también en los cuerpos de aquellos que han sido víctimas en el fuego cruzado. Ejemplo de ello se encuentra en una joven que terminó sus estudios de bachillerato en el año 2015 y que lleva incrustada en su columna una bala de fusil disparada por un integrante de las fuerzas militares del Estado, o de familias que resultaron desplazadas por el temor de perder sus vidas en medio del fuego cruzado, como el caso de una estudiante que tuvo que salir del corregimiento por el riesgo que corría su vida tras los enfrentamientos permanentes entre la guerrilla y la Policía.

Daños ha habido y muchos; hace como cinco años cuando el conflicto armado era demasiado, mi casa quedaba a las afueritas del pueblo y era bastante peligroso estar allí, las balas se escuchaban cerca, las bombas explotaban [...], eso era todo un trauma. Nos tocó irnos a estudiar a otro lugar, jjummm! Bueno, ¿y cómo vamos a llegar, de qué vamos a vivir, qué vamos a hacer? Cuando ya fue bajando la marea regresamos de nuevo porque es como complicado tener 
que irse y saber que el hogar está en otro sitio. (Joven líder y estudiantes del corregimiento de El Plateado, 2016)

Posteriormente, en el año 2010, ante la presión de la población civil fue retirada la Policía de la localidad y a cambio se instaló una base militar en las afueras del corregimiento. Sin embargo, nunca hubo un espacio de confianza de la población hacia las fuerzas militares por las constantes violaciones a los derechos humanos, en su lugar, la presencia de militares para muchos habitantes ha significado riesgo y peligro ante los enfrentamientos que constantemente se dieron en cercanías al casco urbano del corregimiento. No pasó mucho tiempo después de la retirada de los integrantes de la Policía para que la población nuevamente se organizara y obligara a los militares a salir de la zona. Esta acción estuvo motivada por la muerte a manos de integrantes de la Unidad Bronce del Batallón de Infantería n. 56 de un campesino que se desplazaba en motocicleta hacia el casco urbano del corregimiento en el mes de enero del año 2015.

Con la retirada del ejército vendría luego un aparente escenario de mayor calma para la población civil. El ruido de las balas comunes en las noches cedió paso a las risas en los constantes encuentros que empezaron a darse los habitantes en el parque principal del corregimiento, y también al silencio en la medida que avanzaron las noches, luego, con el cese unilateral al fuego decretado por las FARC-EP en el mes de junio de 2015, el caserío entró en un ambiente de mayor paz si así se le puede llamar a estar alejados del peligro de las balas. Luego, con los resultados del plebiscito por la paz en la comunidad y el país se vivió una gran incertidumbre frente a lo que este nuevo escenario representaría en términos de la posibilidad de que se reanudara de nuevo el conflicto armado, sin embargo, con el nuevo acuerdo firmado entre las partes negociadoras, muchos reavivaron la esperanza de que cesara definitivamente el conflicto armado entre el Estado y las FARC-EP en la zona y se generen importantes cambios en materia de inversión social y presencia institucional para la comunidad.

Pese a lo anterior, lo cierto es que una vez refrendados los nuevos acuerdos de paz, a nivel nacional se incrementó la persecución y muerte sistemática de líderes sociales, realidad que se refleja en el municipio de Argelia. Preocupa aún más que no solo es 
la muerte de líderes sociales. En el caso concreto de El Plateado, desde finales del año 2016 y lo corrido del 2017, ya son varias las personas asesinadas, lo cual evidencia que a nivel interno existen otros conflictos y que no solamente la historia de muerte ha sido el resultado de la confrontación armada entre el aparato armado estatal y los grupos insurgentes o por los grupos paramilitares, al contrario, el escenario actual hace visible esa otra cara del conflicto interno que padece la comunidad como resultado de múltiples intereses en la población.

\section{LA VIOLENCIA QUÍMICA EN EL CORREGIMIENTO de El Plateado, el resultado de una política} FALLIDA DE LUCHA CONTRA LAS DROGAS

Los habitantes del corregimiento también han sido víctimas de los programas de fumigación y erradicación manual de cultivos en la zona. Existen denuncias sobre los efectos que se han generado producto de las fumigaciones, proceso que ha cobrado vidas humanas y a su vez afectado de manera transitoria la base económica local y áreas con pequeños cultivos de pancoger. La Red de Derechos Humanos Francisco Isaías Cifuentes (2007) en una denuncia del año 2007, señala que a raíz de fumigaciones aéreas se afectaron no solo los cultivos de coca sino también fuentes hídricas como el río Micay, y en especial la bocatoma del acueducto que suministra agua a la población. En otra denuncia, se indica que durante el mismo año, como resultado de la aspersión aérea de glifosato, un niño perdió la vida tras presentar un cuadro clínico de intoxicación, a la vez que muchas otras personas presentaron síntomas que los habitantes atribuyen a efectos secundarios de las fumigaciones. Realidades como estas son las que ha tenido que padecer la población civil como producto de la implementación de la política antidrogas en la región. En los relatos de campesinos se hacen evidentes los atropellos contra los habitantes, en donde se señala que además de la aspersión aérea de venenos, también se han cometido abusos por el aparato militar del Estado.

Las avionetas vienen y fumigan un día en un corregimiento, el otro en una vereda, el otro en otra vereda, se van y vuelven a los pocos días. Fumigan por encimita de las casas, bien cerquita y la gente tiene que encerrarse porque las 
casas quedan sucias, pobladas de glifosato, ¡cogieron una loma y tenga! por encima de la escuela, por encima de lo que encontraron [...], eso es terrible, no respetan nada [...] fumigaron toda la bocatoma del acueducto, toda la fumigaron [...] aquí decimos que las avionetas pasan tan cerquita de los techos de las casas que ya las podemos bajar a machetazos [...] unas gallinas se murieron y las que no se las ha robado o comido el ejército, las que se murieron fue porque picaron en los huertos los maduros que quedaron después de la fumigación, ¡y tenga! Hasta allí llegaron. Mientras tanto, mientras eso pasa, el ejército llega a atacar a la población, abusando, quitando desde una bomba de fumigar en adelante [...], han extorsionado a la gente, le piden plata o le dicen que le dan unos pesitos para que no hable, para que no denuncie lo que ellos hacen [...] jah! Y otra cosa, a un señor le quemaron la casa, quemada del totazo, el tierrero que quedó. (APAPSCO, 2007, párr. 10)

En medio de estas realidades, los cultivadores de coca también se idearon diferentes mecanismos para impedir que las aspersiones con glifosato acabaran con los cultivos, situaciones un tanto ocurrentes pero que, según personas de la región, a muchos les dio resultado en su momento.

Aquí dos veces fumigaron, la gente corría a tapar con plásticos para proteger de ese veneno los cultivos, empezaron a colocar en los cultivos que quedaban en lo huecos a templar alambres para que se enredara la avioneta [...] pero no lo lograron. Eso desde arriba en donde coge para La Belleza hubiera visto cables de lado a lado y me acuerdo un cuńado que iba a colocarle chuspas a las matas y a enterrarlas [...], las matas que eran grandes las doblaba y les echaba tierra encima para que no le cayera glifosato [...], la gente se inventaba un poco de cosas [...], eso se puso malo, ahí se formaron ladronicios tremendos, atracos en la vía [...], ahí si no se podía dejar la casa sola, ¡ahí sí que daba miedo! (Exdocente Institución Educativa Técnica Miguel Zapata, 2016)

En un hecho sucedido en el mes de noviembre de 2015, como resultado de un intento de erradicación manual desarrollado en el municipio de Argelia, se generó todo un panorama de tensión social, situación que dejó como saldo varias personas heridas y también la pérdida de la vida de uno de los campesinos manifestantes 
en contra del proceso de erradicación. Tras una reunión entre las comunidades y el Gobierno, finalmente se llegó al acuerdo de instalar una mesa de interlocución para discutir el tema de los cultivos de coca y desarrollo agrario, con lo cual se logró suspender temporalmente la acción ordenada por el Estado.

Los cultivos de coca no solo trajeron violencia armada, también la violencia química del Plan Colombia con sus fumigaciones cobró vidas de personas que hacen del cultivo su sustento de vida. Es común también encontrar en el territorio numerosos casos de personas con algún tipo de discapacidad física que según los pobladores son el resultado de las fumigaciones con glifosato. En este sentido, las dinámicas desarrolladas en la economía local significaron "progreso" para algunos que lograron acaparar importantes sumas de dinero a partir del cultivo, procesamiento y tráfico de cocaína, para otros ha significado muerte, desplazamiento y desaparición. Para la naturaleza ha significado tala indiscriminada, deterioro de suelos, uso intensivo de agroquímicos, contaminación de fuentes hídricas, en general, pérdidas de la base principal para la producción sustentable de alimentos. Para la comunidad en general ha significado el sustento económico por más de 30 años, periodo que ha estado atravesado por épocas que ellos llaman bonazas y también por periodos de crisis en momentos en que el Estado arremetió con las fumigaciones en el marco de la política de lucha contra las drogas del Plan Colombia, o ante las amenazas de erradicación manual en los últimos años. El Plateado, como se escucha en alguno de los relatos, "es vivir en medio de la abundancia, pero también en medio del conflicto, en medio de las balas" (campesino habitante de la región, 2016). Es un lugar que para algunos genera un sentimiento de orgullo a pesar de sus momentos de cruda violencia.

Pese a ello, son muchas las expectativas y a su vez los temores que se generan en la comunidad luego de concretarse el acuerdo de paz entre el gobierno y las FARC. En este sentido, un líder comunitario del corregimiento hace la siguiente radiografía y plantea algunos interrogantes que se derivan de la realidad que se vive en la región.

Nosotros hemos vivido 30 años con la guerrilla, conocemos cómo es la guerrilla y hemos podido desenvolvernos y movernos en medio del conflicto, lo conocemos a la perfección y si uno se mete en problemas es porque quiere, 
eso lo sabemos bien; pero no sabemos si en el posconflicto seamos capaces de manejarlo porque seguramente van a haber otros actores que van a generar otros conflictos, están las mafias, las Bacrim, van a quedar reductos de la guerrilla, es decir van a estar otros actores [...], pueden llegar tal vez las mafias y organizar a la gente para que se defienda, o tal vez las Bacrim que siguen siendo los mismos paramiltares [...], no sabemos qué pueda pasar. ¿Qué va a pasar con el otro actor armado presente en la zona que no está en la negociación? Tampoco sabemos. (Líder comunitario del corregimiento de El Plateado, 2016)

\section{LOS INTERESES DE LAS TRASNACIONALES MINERAS EN EL ESCENARIO LOCAL, EL FRUTO DE UNA POLÍTICA NACIONAL QUE REPRIMARIZA EL CAMPO}

Hay que manifestar que la agudización del conflicto armado de los últimos años no ha obedecido solamente a una coyuntura asociada al narcotráfico. También existen denuncias que muestran la otra cara del conflicto, en donde se tejen intereses económicos en zonas estratégicas del suroccidente colombiano.

La militarización ha sido acompañada de maltratos físicos y psicológicos hacia los habitantes de estos lugares. Tropas de la Brigada XIX del Ejército con efectivos de los batallones General José Hilario López, Boyacá, Grupo Cabal, Contraguerrillas 37, 57 y 92, del Alta Montańa n. ${ }^{\circ}$ 4, Fiscalía, DAS, SIJIN y el Grupo Paramilitar Águilas Negras, escudadas en el argumento de una persecución hacia la guerrilla de las FARC-EP, han incinerado varias casas de estas poblaciones, dejado explosivos en lugares cercanos a la comunidad, extorsionado, robado, perseguido, seńalado, allanado y asesinado a varios campesinos de estas regiones en el marco de dichas operaciones. Tras la realidad de estos hechos se encuentra oculta la materialización de una política de desterritorialización y reterritorialización, dirigida a expropiar y desplazar a los habitantes de estos municipios para poner en marcha grandes proyectos de cooperación internacional que garanticen la permanencia del sistema del capital. (APPSCO, 2007, párr. 6) 
La minería, en el marco de la política minera nacional, se constituye en una amenaza que genera interrogantes en los pobladores de la región. ¿Cuál será la realidad futura del corregimiento frente a los actuales acuerdos de paz del gobierno nacional y las guerrillas de las FARC-EP? ¿La intensión de apertura de una ruta de la vía Panamericana hacia la costa pacífica por el territorio del municipio de Argelia tendrá como fin último generar las condiciones para la explotación de recursos mineros, agua y biodiversidad del macizo colombiano y del mismo municipio de Argelia? ¿Los procesos de militarización tendrán como fin generar condiciones para que las trasnacionales mineras devoren las montańas como lo han hecho los cultivos de coca con el bosque nativo? ¿La constante ayuda humanitaria de organismos internacionales tendrá como fin paliar algunos efectos generados por las dinámicas de un conflicto que ahora va detrás de otros intereses? Estas y otras preguntas se cruzan en la memoria de algunos pobladores que ven con recelo y preocupación el devenir futuro de la población. Coca y violencia han sido dos términos llenos de contenido y efectos en las mentes y los cuerpos de la población plateadeña, y en general de todas las zonas que han vivido de las economías del narcotráfico, pero ahora parece ser que se vislumbran otros horizontes posibles en donde se conjuguen minería y violencia, tal como ya está sucediendo en lugares no muy lejanos del corregimiento, caso concreto la violación de derechos humanos bajo la avanzada de la política minera en los municipios del macizo colombiano.

Esta posibilidad no está tan alejada de la realidad local, en el mes de abril de 2016 llegó al despacho de la alcaldía municipal de Argelia un comunicado de la Agencia Nacional Minera en donde se informaba que desde el año 2009 más de 1.950 hectáreas hacen parte de la propuesta de concesión minera KLF-08021, presentada por Anglo American Colombia Exploration S. A. y que además la alcaldía municipal tenía 30 días hábiles para soportar con estudios técnicos, sociales y ambientales su oposición frente al proyecto.

De acuerdo con el reporte periodístico presentado en el diario El Nuevo Liberal el 22 de mayo de 2016, serían alrededor de 13 las solicitudes en concesión minera para la explotación de cobre y sus concentrados, situación que evidencia un panorama local bastante complejo. Ante esta situación, se siente el temor no solo desde los entes gubernamentales locales, sino desde las mismas comunidades que no se explican 
cómo mientras se habla de buscar un acuerdo de paz, a nivel local las comunidades tienen que verse enfrentadas a los intereses económicos de las grandes trasnacionales mineras.

Ante este panorama, el sonido de las retroexcavadoras y todo el poder oculto detrás de estas, parece ahora amenazar con carcomer el subsuelo de corregimientos como La Belleza, en su afán de búsqueda de materiales como cobre para seguir alimentando la insaciable industria capitalista, mientras tanto, la legislación nacional en la materia abre las puertas para la intervención en los territorios.

\section{APUNTES FINALES PARA LA DISCUSIÓN}

A partir del recorrido en parte de la historia de un corregimiento que ha vivido y vive de los cultivos de coca, es evidente cómo el Estado colombiano no logró generar las condiciones suficientes para que las comunidades campesinas desarrollaran un modelo económico sustentado en cultivos legales, su escasa presencia institucional se remonta al intento de dominio del territorio con el aparato armado del Estado y a la aplicación de una política fallida de lucha y combate de las drogas. Tal ausencia institucional terminó generando vacíos que fueron llenados por otros actores armados que ejercieron control del territorio y que también, de alguna manera, aportaron al desarrollo de infraestructura en la localidad. Ejemplo de ello parte de la construcción que conforma la sede principal de la Institución Educativa Miguel Zapata, en la cual, según los habitantes, se contó con la colaboración de las FARC para su construcción.

Otro asunto importante de mencionar es que reconstruir la memoria colectiva de vida en el escenario local permite vislumbrar que no todo el tiempo la comunidad que habita este lugar ha dependido de los cultivos de coca, al contrario, en sus inicios la diversidad de cultivos y las relaciones comunitarias que se dieron eran propias de las economías campesinas, que basaban sus relaciones sociales en lazos de solidaridad y cooperación. La llegada de los cultivos de coca significó para la localidad y sus alrededores la ruptura no solo de sus sistemas de producción, sino también de las relaciones sociales a partir del flujo constante de población atraídas por las promesas 
del narcotráfico, situación que generó una crisis de identidad por el constante encuentro y desencuentro entre habitantes provenientes de diferentes lugares.

Comprender los proceso de ocupación del territorio por parte de cada uno de los actores que están presentes y que de alguna manera guardan relación con la economía de la zona, se constituye en un factor imprescindible para trazar pistas que permitan estructurar nuevas apuestas educativas y económicas que busquen resquebrajar la matriz cultural predominante en la zona, en donde el dinero derivado de lo declarado como ilícito desde la institucionalidad estatal y la violencia, se han incorporado o más bien naturalizado dentro de la vida social comunitaria. La violencia y la confrontación armada entre los grupos insurgentes y militares del Estado colombiano o contra grupos paramilitares, ha dejado historias de dolor y miedo imborrables en las memorias de quienes han tenido que vivir en carne propia la pérdida de sus familiares o amigos, como producto de un conflicto ajeno que también llegó con los cultivos de coca.

Estas historias necesitan ser escuchadas y escritas desde el seno de la misma comunidad, puesto que se constituyen en insumos para el reclamo ante el Estado de los atropellos a los que han sido víctimas y también como parte de esa memoria colectiva, que si bien es difícil de olvidar, aún quedan esperanzas de un mejor futuro. Frente a esta situación, hacer memoria de la historia colectiva permite reconocer parte de esos conflictos sociales y cambios socioculturales que se han dado en el corregimiento, historia que es desconocida para muchos jóvenes y que necesita ser incorporada en espacios como los centros educativos, organizaciones de base campesina, entre otros, como aporte para la construcción de una identidad colectiva desde los espacios juveniles. Desde luego que la memoria reconstruida frente a la llegada y desarrollo de los cultivos de coca en el corregimiento de El Plateado no agota por completo relatos y vivencias de la vida colectiva en el escenario local, los elementos históricos aquí reconstruidos son un primer insumo para empezar a generar diálogos frente a ese pasado que ha caracterizado la vida en esta localidad.

Por lo tanto, la historia local no es una simple narración de hechos sucedidos en el pasado, más bien, es la posibilidad misma que tienen los actores directos para 
generar dinámicas organizativas que permitan reafirmar las historias narradas, o por el contrario, buscar otros rumbos que den un mayor sentido a la vida individual y colectiva. La notoria preocupación de muchos jóvenes y también de adultos frente a situaciones como los impactos ambientales que han generado los cultivos de coca, y ante lo cual las instituciones competentes parecen ser impotentes, es un síntoma de la necesidad de buscar otras alternativas desde el seno de la comunidad, dirigidas a la recuperación de la diversidad ecosistémica que por muchos años caracterizó la región. Desde luego que la posibilidad de cambiar el rumbo de la historia no está solo en manos de los actores directos de la misma, será necesario el acompañamiento del Estado con toda su institucionalidad y los recursos económicos suficientes para generar en el tiempo las condiciones materiales apropiadas y duraderas, que permitan pensar en otras economías alejadas de lo catalogado como ilícito.

\section{REFERENCIAS BIBLIOGRÁFICAS}

APASPCO - Agencia de periodismo alternativo y popular del suroccidente colombiano. (2007). Las avionetas ya las podemos bajar a machetazos. Recuperado de http://www. colectivodeabogados.org/LAS-AVIONETAS-YA-LAS-PODEMOS-BAJAR

Benavides, F. (2012). Conflicto armado, instituciones y gestión ambiental en Colombia: dimensión ambiental de las políticas públicas de gobierno nacional para atender a la población en situación de desplazamiento forzado. (Trabajo de grado). Bogotá: Pontificia Universidad Javeriana, Facultad de Estudios Ambientales.

Bustamante, D. (2016). El Plan Colombia o el olvido de Macondo. Revista Semana. Recuperado de http://www.semana.com/opinion/articulo/el-plan-colombia-oel-olvido-de-macondo-opinion-de-david-bustamante/460355

Castaño, E., Bernal, M. E., Marín, G., y Ramírez C. J. (2003). Análisis Económico del cultivo de la coca Erythroxylum coca $\mathrm{Al}$ en Colombia. Cultura y droga, 8(10). Manizales. Recuperado de http://vip.ucaldas.edu.co/culturaydroga/downloads/Culturaydroga10_09.pdf 
Comisión Nacional de Reparación y Reconciliación. Grupo de Memoria Histórica. (2009). Despojo de tierras y territorios, aproximación conceptual. Bogotá, Colombia: Editorial Comisión Nacional de Reparación y Reconciliación - CNRR, Instituto de Estudios Políticos y Relaciones Internacionales - IEPRI y Universidad Nacional de Colombia.

Daza, P. A. (2016). La coca y su impacto en la economía del Cauca, Popayán. Utopía Textos, primera edición.

El Nuevo Liberal. (2016). Argelianos reclaman concesión de nuevo título minero en su territorio. Recuperado de http://webcache.googleusercontent.com/search?q=cache:MxDXaLUUWEUJ :elnuevoliberal.com/argelianos-reclaman-por-concesion-de-nuevo-titulo-minero-en-su-ter ritorio $/+\& \mathrm{~cd}=5 \& \mathrm{hl}=\mathrm{es} \& \mathrm{ct}=\mathrm{cln} k \& \mathrm{gl}=\mathrm{co}$

Kalmanovitz, S. (2007). Colombia en las dos fases de globalización. Revista de Economía Institucional, 9(17), 43-74.

Kalmanovitz, S. (1999). Las instituciones colombianas en el siglo XX. Borradores de Economía número 131. Recuperado de http://repositorio.banrep.gov.co/bitstream/handle/20.500.12134/5149/BORRADOR\%20131.pdf?sequence $=1$ \&isAllowed=y

Molano, A. (2015). La noche del campesino. El Espectador. Recuperado de http://www. elespectador.com/opinion/noche-del-campesino

Molano, A. (2012). En medio de las balas. El Espectador. Recuperado de http://www.elespectador.com/noticias/nacional/medio-de-balas-articulo-361891

PNUD Colombia. (2011). Colombia rural, razones para la esperanza. Informe Nacional de Desarrollo Humano. Recuperado de https:/www.undp.org/content/dam/colombia/docs/ DesarrolloHumano/undp-co-ic_indh2011-parte1-2011.pdf

Red de Derechos Humanos Francisco Isaías Cifuentes. (2007). La fuerza pública colombiana a diario esparce veneno sobre las fuentes de agua que suministran los acueductos en el municipio de Argelia. Recuperado de http://www.reddhfic.org/index.php?option=com_content\& view=article \&id=106:argelia-2-marzo-2007\&catid=45:acciones-urgentes-cauca-2007\& Itemid $=88$ 
Registro Único de Víctimas. (2016). Registro Único de Víctimas - RUV. Recuperado de http:// rni.unidadvictimas.gov.co/RUV

Rivera, Y. (2013). Los derechos de propiedad: un elemento central para el desarrollo económico. Revista Estrategia Organizacional. UNAD. Recuperado de http://hemeroteca. unad.edu.co/index.php/revista-estrategica-organizacio/article/download/1516/1817

Rodríguez P. (2010). El Mambe. Fronterad. Recuperado de http://fronterad.com/?q=mambe

Rutas del conflicto. (2007). Masacre de El Plateado. Recuperado de http://rutasdelconflicto. com/interna.php? masacre $=658$

Soria, C. (s.f.). ¿Cómo conceptualizar el derecho consuetudinario? Recuperado de https:// dialnet.unirioja.es/servlet/articulo?codigo $=5109971$

Urbano, D., Díaz, J. C., y Hernández, R. (2007). La teoría económica institucional: el enfoque de North en el ámbito de la creación de empresas. Decisiones basadas en el conocimiento y en el papel social de la empresa, 2, 1-15.

Verdadabierta.com. (2014). La larga y cruel lucha por la tierra en el Cauca. Recuperado de http:// www.verdadabierta.com/lucha-por-la-tierra/5087-la-larga-y-cruel-lucha-por-la-tierraen-el-cauca 